\title{
INTANGIBLE CONTRIBUTIONS TO SOCIETY: THEIR VALUES AND POTENTIAL EXCHANGE FOR MONEY
}

\author{
Thomas L. Saaty \\ saaty@katz.pitt.edu \\ Jennifer S. Shang \\ shang@katz.pitt.edu \\ The Joseph M. Katz Graduate School of Business \\ University of Pittsburgh \\ Pittsburgh, PA 15260 \\ USA
}

\begin{abstract}
This paper summarizes some of the current efforts around the world to deal with the intangible compensation and relate it to the monetary system. The value of benevolent acts must be linked in small steps through important criteria so that their relative worth can be determined through numerical priorities. A hierarchical structure with priorities and pair-wise comparison matrices are developed to show the relationship between the smallest altruistic acts of people and those involved large life-time sacrifice. This should make it easier to convert compensation for all sorts of intangible acts to equivalent monetary value.
\end{abstract}

Keywords: intangible, benevolent acts, contribution, exchange, monetary value

\section{Introduction}

There are many contributions and acts of kindness that add to the richness of society and go unrewarded because we have no established ways to recognize them all and include them in our ongoing reward and compensation system. Many people serve society by giving of themselves in ways that are not like a regular job but nevertheless are important contributions to social welfare. They are not compensated with money that has durable value and are often spontaneously rewarded with words of appreciation, certificates and mementos or with words of praise in the media and that is the end of them. Such acts inevitably involve time and effort and frequently also labor that under different circumstances is compensated monetarily. Sometimes the individual that does the act of kindness is wealthy and may not have the need to get more money nor even receive recognition. More often the person is not so fortunate economically and an act of kindness by them may be worth translating to economic value.

In any case there is an unspoken and undeveloped area of human activity that is worth examining for reward and compensation. A major difficulty so far has been that of identifying such acts in terms of time, effort and impact. Most of the time they are separate actions that do not fall under some kind of rubric to be recognized as regular work, yet their impact can be significant and have a lasting value. "The buck stops here" was Harry Truman's favorite aphorism. He had something else in mind, a certain higher and perhaps nobler purpose than can be bought with the buck.

The crisis of unemployment and poverty in America continues to worsen, as evidenced by the near ten percent unemployment rate and more than five million jobless citizens. Unemployment means steep decline in monetary income. Laid-off workers suffer the worst and become poor in this economic climate. 
Economic devastation seems an inevitable cycle in the market economy. Market economy depends on individuals' self-interest. The self interest-based system in the current society is responsible for the ordeal people are enduring. It seems wrong to build a society's exchange system rooted solely in economic value. Too many unhappy people are present in this currency-based world. A society focuses only on monetary value is not a system conducive to citizens' happiness. In the monetary-based economy, happiness is not easy to pursue for those less privileged, because their needs are restricted by the limited currency available. Even the privileged spend time worrying about money and how to spend it. In this paper, we explore a different value system in a society where besides currency people can acquire credits for their intangible services to society. Interestingly enough, the University of Pittsburgh's Staff Association Council has proposed "non-monetary compensation alternative for staff in lieu of salary increase for fiscal year 2010."

At this time, many people are unemployed and suffer from lack of resources to eat or to have a roof over their heads. Yet, they do have ample time to make contributions to enrich society. Such active contribution should earn them a new kind of credit which in the scheme of things ought to be translatable to satisfy their needs for mere survival. However, it seems that right now society has a major problem to meet all citizens' needs by relying directly on money alone. Money itself is suffering from mismanagement by financial institutions who regrettably appear to take advantage of the hard work and savings of ordinary people.

An altruistically-motivated interest generates much of the value in society. For example, housework, care-giving, and voluntary activities constitute a major segment of human wellbeing. The United Nations Human Development Program (Gaye, 2007) reports that only about half of the world's human time spent on "productive activities" was going through formal markets and reported in GDP. Many endeavors that are critical to the survival of a modern society are unpaid. Examples include neighborhood crime watch, prevention of industrial pollution, and reduction of ozone depletion. Volunteer activities like doctors without borders who provide urgent medical care in countries to victims of war and disaster regardless of race, religion, or politics are other examples. Since only paid work is "real" work, the connective tissue that holds the entire society together- trust, reciprocity, and civic engagement, simply goes unaccounted for. To ensure that the world functions humanely beyond money and behave consistently with cherished principles, we need to develop a new system to explicitly include normative values - family, neighborhood, community, city, country, and the whole world who drive the creation of a diversity of intangible values.

For human beings, besides health, it is widely recognized that supportive friends and close family are a source of happiness. Having goals and progressing toward them, such as to learn, to grow and to overcome challenge at work and in personal development adds life satisfaction. Work whether paid or not enriches life; an altruistic connection to something larger than physical-self makes life more meaningful. Many people have noted that money as the only measure of value in this world is inadequate to make people happy. There is no denying that tangible wealth is important. But using money as the only measure of worth is not sufficient. Alternative instruments as those described in this paper need to be developed and circulate widely to give recognition of worth to individuals who are willing and able to contribute to benefiting others in what now are intangible ways for which they get no palpable recognition.

As we shall see below, the idea of compensating people for what might be considered as contributions that are not strictly economic but humane and intangible is by no means original. What is original in this research is we provide a way to measure the importance of such intangible acts in relative terms so that when desired they can be converted to monetary units or credits in a systematic way. To ensure that our world functions with adequate consideration of all the good things people do beyond the use of money and responds with consistency to cherished principles, we need to develop a new system to explicitly include normative values for all the good deeds of people. In extreme cases they can include family and 
friends, but otherwise they should include neighborhood, community, city, country and the whole world that benefit from the creation of a diversity of intangible values.

The value of human acts does not have the permanence that objects manufactured by industries that consume resources in the form of labor and materials have. Human acts vary with the circumstances in which they are applied. Therefore we cannot hope to ascribe to them a constant (absolute) value for all time as we do with objects. We can only measure them in terms relative to similar acts with which they are compared, and the amount of efforts and time needed to perform these acts and perhaps also the impact they produce. Thus we need to perform comparisons within a variety of typical circumstances to develop some kind of permanence of the value of acts within a group of situations after we have categorized these situations. The question is then how to perform such comparisons to produce both a meaningful and a useful way to measure intangibles and convert it to dollars when needed.

\section{Examples of societies with less money-dependence}

\subsection{The happiness index in Bhutan}

Among the 195 countries in the world, Bhutan, a financially poor Himalayan kingdom, is the only country in the world which deems happiness (a somewhat intangible concept) essential to its government policy (BBC News, 2006). The Bhutan government puts inner spiritual development on a par with material improvement. It is not only concerned about GDP but also about Gross National Happiness. Happiness-politics makes the country look beyond physical wealth; anything that does not contribute to happiness is discouraged. As a result, advertising is banned in Thimphu, the capital; wrestling, MTV, plastic bags, and tobacco are forbidden. On the other hand, conservation laws are painstakingly decreed to achieve a sustainable environment. It has even banned plastic bags on the grounds that they make the country less happy. The one set of traffic lights Bhutan ever had people found frustrating, so they went back to a person directing traffic. Buddhist prayer flags flutter in the wind. Happy citizens are the ultimate goal of the government policies.

\subsection{Yufu in Japan}

This subsection is based on the report written by Tim Larimer (2006) for Time, Asia. The residents of Yufuin, Japan, a tiny hot-springs town have been recession ravaged. They suffered economic difficulties with low-paying and seasonal tourism-related jobs. To resolve predicaments, residents improve their standard of living by printing their own version of currency to increase their local money supply and solve a chronic yen-flow problem. Using the locally printed currency, yufu, residents can take a taxi, buy wine, eat lunch, buy a ticket, etc. Thus residents in Yufuin have their own strong currency and are not subject to what the national government does.

The yufu scrip has value because villagers agree that it does and use it that way. The system is a form of barter. Resident belongs to a club. Each club has more than 100 members and offers service to exchange yufu. For example, one woman teaches people how to wear kimonos, an unemployed man gives haircuts, and several townsfolk sell rides in their cars. In Yufuin, people won't accept money, but they'll accept yufu. Barter allows villagers with little cash to trade labor for life's necessities.

The community's adventure in economics has inspired dozens of other towns across Japan to dabble in their own currencies. In other countries, barter clubs are frowned upon because they can be used as a glorified tax dodge - people don't have to report yufu revenue, for example, or pay Japan's national 5\% sales tax. But Japanese officials reckon that if it helps strengthen solidarity in a local community, that's good. Checks and balances exist. Every yufu user is required to sign the notes they issue. Ultimately they will be called upon to redeem those notes by performing a service for the bearer. 


\subsection{Local Exchange Trading Systems}

The subject matter discussed in this subsection is based on The LETSystem Design Manual (2009). Local Exchange Trading Systems (LETS) are local, non-profit exchange networks where goods and services are exchanged without using currency. Michael Linton coined the term LETS in 1983 and briefly ran the LETSystems in British Columbia, Canada. Some Australians built houses using LETS in place of a bank mortgage, freeing owners from onerous interest payments. Unlike direct barter, members in LETS are able to earn credits from any member and spend them with anyone else in the system. Interest-free local credit is used so direct swaps are not necessary. An individual may earn credit by working on job A for person X and spend it later on job B with person Y. Since transactions are recorded centrally and credit is issued by the network members for the benefit of the members, they are regarded as mutual credit systems.

LETS revitalizes community by allowing individuals, small businesses, local services and voluntary groups to cooperate and to extend purchasing power. It is especially beneficial in stimulating the economies of financially depressed community that have goods and services, but scarce of currency. Generally, a conventional national currency is hard to earn but easy to spend. In contrast, LETSystems are comparatively easy to earn but harder to spend. The success of a LETSystem is therefore determined by the ease with which a person can spend their LETS credits, and improve their quality of life by participation. LETS are present in many countries. Examples include those in South Africa, New Zealand, Australia, Israel, USA, Norway, United Kingdom, Europe, Japan, South Korea, etc.

Societies regularly have people idle; millions right now in US due to economy downturn. To realize their value and cash in their potential, a flexible exchange and evaluation system is necessary. It is important to design a practicable evaluation system to measure the value of different tangible and intangible contributions, so that materials, equipments, skills, time, and goods can be put into use and people's need can be satisfied. An objective valuation system will help spread out trading concept like LETS and benefit societies. In the following section, we apply the AHP-based multi-criteria decision making method to prioritize various activities that do good to the public and benefit humanity.

\section{Applying the AHP to prioritize benevolent acts that benefit society}

People can create value as long as they are alive and healthy. Under the system proposed in this paper, individual's non-monetary related efforts can be recognized. When voluntary activities and random act of kindness are acknowledged, much dormant potential in the society gets developed and awakes. The system we create in this section allows the exchange of intangibles (social units) in the free market. It brings the idea of marketability concept to help remove the burden of today's crisis. The reason why we must create "units" is because people may not be truthful with each other if no unit is used. Secret activities undertaken by two or more people for the purpose of fraud may occur. Collusion may be acceptable between two people, but it is not right when an entire community is involved. In this section, we propose creating "social units". Having such a system would eliminate some anguish many human beings who have little monetary wealth in this world may sense. We feel that it would be useful to make the world know that there is a way to live an "affluent" life even without money.

Most people accept the fact that diamonds are more valuable than water, even though water is one of the most precious substances on earth. The reason is because market values are frequently irrelevant to social or ecological values. This implicitly proves that existing market does not fairly reflect human value socially, ecological, politically. We intend to change the system that people are accustomed to, a system people desolately rely on at this time.

The AHP method we employed in this paper can be used to reflect judgments on opinions and emotion. The result is a prioritized ranking, expressing the preference for different alternatives. The AHP takes use 
of principles of decomposition, comparative judgments, and synthesis. Decomposition requires building a hierarchy to represent a problem, by locating the goal of the decision problem at the top, and placing the criteria, subcriteria, and alternatives at descending level of the hierarchy. For comparative judgments, one arrange a comparison matrix at each level to compare pairs of (sub)criteria or pairs of alternatives.

The fundamental scale for pairwise comparison ranges from 1 (indifference) to 9 (extreme preference). Through synthesis, the complete pairwise comparison-matrices are able to estimate the relative priorities for all alternatives. At the end, the AHP not only provides the rank order information, but also the ratio scale of each alternative. It is well recognized that the presence of intangibles adds a new dimension of complexity to any decision making problem. Evaluating intangible contributions to society is difficult due to their subjectivity. Without a systematic approach, the decision maker may deal with the problem intuitively, causing partiality, inaccuracy, and inconsistency. The AHP method offers a valuable tool to deal with qualitative and intangible issues.

In this section we focus on the altruistic acts that people offer to advance the society. Subsection 3.1 discusses the basic human needs, which serve as the criteria for evaluation. The example in Subsection 3.2 is meant to give a formal approach to analyze and draw the attention of readers to matters about which the public is usually involved and contributed. Our hope is to invite a broader and objective look at the value of many people's contribution, and encourage more people to devote their time and money to benefits human wellbeing. The views expressed here are drawn from discussion with our colleagues, newspapers, internet articles. They form the basis for constructing the hierarchies and judgments in Subsection 3.3. The variables used in the model, and the values assigned to them, are purely illustrative. Nevertheless, it would not diminish the importance of the idea we are presenting in this paper. In the following, we discuss the different types of endeavors people, with little or no recompense, undertake to serve the society. Those viewpoints work as foundation for guiding the readers through the idea of recognizing the value of many important valuable inputs people contributed to the world.

\subsection{The evaluation criteria}

Human beings are living animals who have many basic needs. Maslow (1943) identified five fundamental human needs and their hierarchy bottom up as: physiological, safety, belonging, esteem, and selfactualization needs. In this paper, we modify Maslow's five basic needs and apply them to the evaluation of the altruistic activities people regularly contribute to the society. They are shown on the top of Figure 1.

Physical needs are those necessary for maintaining the human body, including food, clothing, shelter, health, etc. In terms of social needs, people require safety and sense of belongings. Safety keeps people from harm. A rich, strong, and powerful person who has lots of social network and support can make him/herself safer. Belonging needs are related to love, affection, being a part of groups, etc. Being helpful and kind to others will make a person more desirable as a friend and in turn he will feel more integrated to that group or society.

In the emotional front, esteem needs require one to gain more respect from others or to feel powerful. Self-actualization needs are to achieve individual potential and become what one is capable of becoming. Environmentally, one needs to protect earth and ecosystems. Not only fresh air, but also clean water, and nature need to be preserved. Garbage and waste need to be timely and completely removed, processed and cleaned. Finally, incidental needs are unexpected requirements or requisite not necessary of prime importance. They may come as an emergent need or in an incidental manner, not of central or critical importance to the integral of the society. After identifying all the pertinent evaluation criteria, we are ready to assess different types of altruistic conducts. 


\subsection{The altruistic undertakings}

The multiple levels (modest, intermediate, and big) of altruistic activities shown after evaluation criteria in Figure 1 form the alternatives of the proposed AHP model. Among them, we divide modest acts into two levels, intermediate acts into two levels, and big acts into 3 levels, named S1, S2, M1, M2, L1, L2, and L3 respectively. Altruism promotes self-sacrifice for the happiness of others and loves others as oneself. Altruists align their well-being with others: they are happy when others thrive, sad when others struggle. However, it seems the biggest obstacle that holds back altruism in our society right now is the monetary system. The money system creates an artificial state of mind, and establishes zero-sum relationships between people. It promotes competition instead of cooperation in the world, and makes people believe helping others will weaken themselves. Thus, money system places an unhealthy emphasis on individuals and that wears down the society and feeds depression. In this section we develop a model to value the contributions individuals and organizations made to the society, and using such a system to complement the money-based society to create a sense of abundance for all human beings throughout the world.

\section{(A) Modest Acts}

Modest acts are selfless deeds, performed by individual(s) to enliven others, either spontaneous or planned, to make people happy. Examples of small kind acts given in Level S1 are being courteous and agreeable, giving small gifts, complimenting people, keeping company and comforting elderly (note that activities in italic font can be found in Figure 1). Modest acts encourage the positive, caring side of human nature. The underlying assumption is that people want to maximize their happiness, while one's happiness often hinges upon seeing other people happy. Gratitude and thankfulness is to acknowledge and honor other people's value, while touch and hug is a form of physical connection. Like surprising people with covert gift, they are acts of love given with great tenderness and thoughtfulness.

As shown in Figure 1, the modest acts given in S2 level are voluntary deeds performed without pressure. Besides economic-based, they include individual's unadulterated intentions of looking out for society's common good and giving from the heart. Generosity is a reflection of individual's passion to others. Unselfish behavior in this level could evolve from people to animals and nature. Many believe that life on earth is being threatened, as evidenced by environmental disaster, and potential green house effects and climate change. Cleaning and caring environment not only shows the love for the nature, but also for the ecosystem which the lives of human beings depend on. Teaching and educating opens the door for people to learn, to appreciate the beauty and the world. It helps individuals find the best in themselves and contributes to the joy of life. Whether it is formal or not, education is an essential component of success for most people. Helping the needy and the poor is more than an action; it's an attitude of caring and willingness to serve others. It is an important trait many people consider important to cultivate in life.

(B) Intermediate Acts

True compassion is more than offering the modest acts described above. Besides playing the Samaritan on life's roadside, people serving the community may also regards a society having many poor and needy people as one that requires restructuring. So, besides undertakings such as donating to the United Way and Red Cross, fund raising, providing social work, devoting time to serve and build communities become an important option that affords one with the opportunity to change the society in a larger scale.

One may choose to serve the community through running for public office. But before one gets elected to hold an office, a person may choose to serve the smaller society by working as a community organizer, like president Obama did in Chicago. Community organizing brings together people in proximity to act in their common self-interest and help community building. The community may see conflict and social 
struggle as necessary to generate collective power for the powerless. Often local leaders and coalition facilitators arise and leadership of grass root is developed. Micro Lending 1 is also an important aspect of 
Table 1. The AHP model to prioritize the benevolent acts

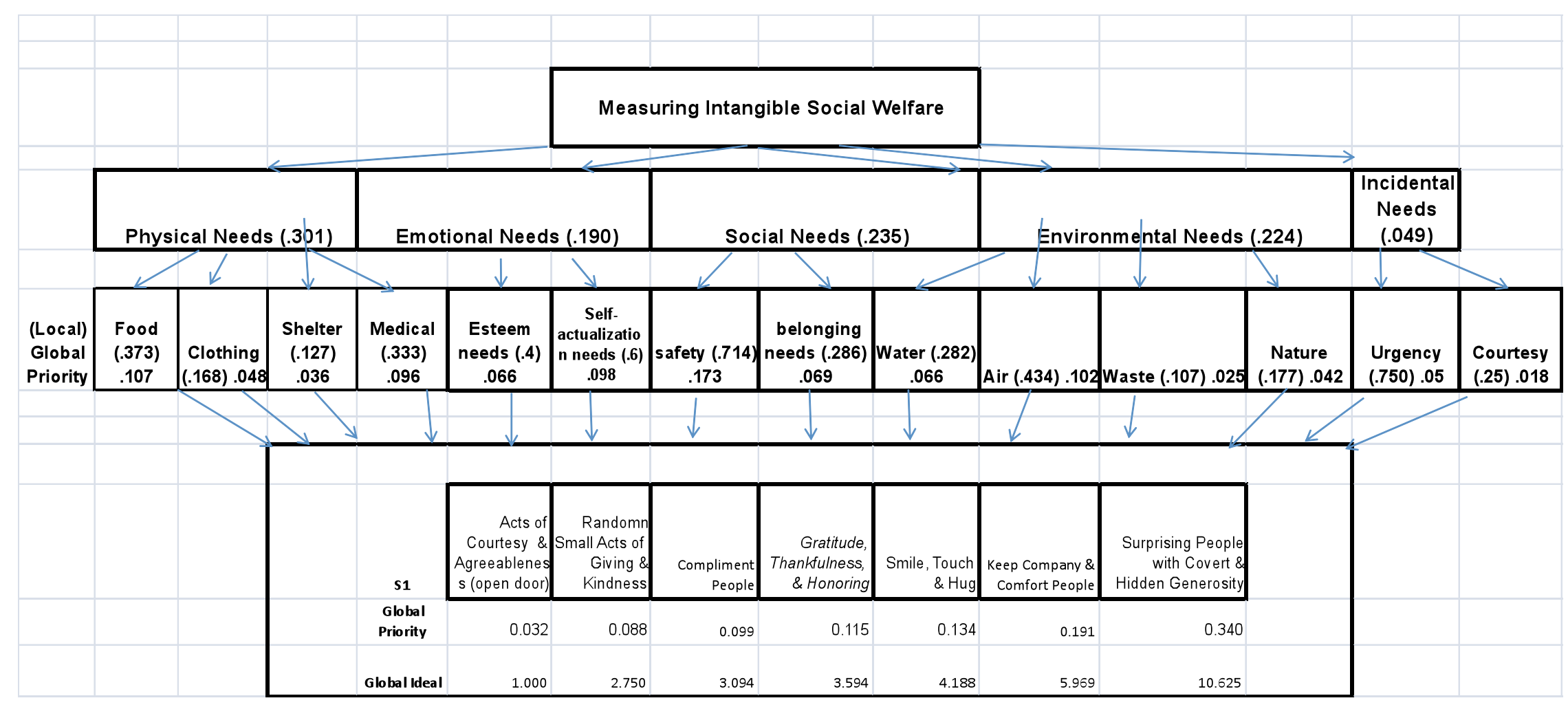


Table 1. The AHP model to prioritize the benevolent acts (Continued 1)

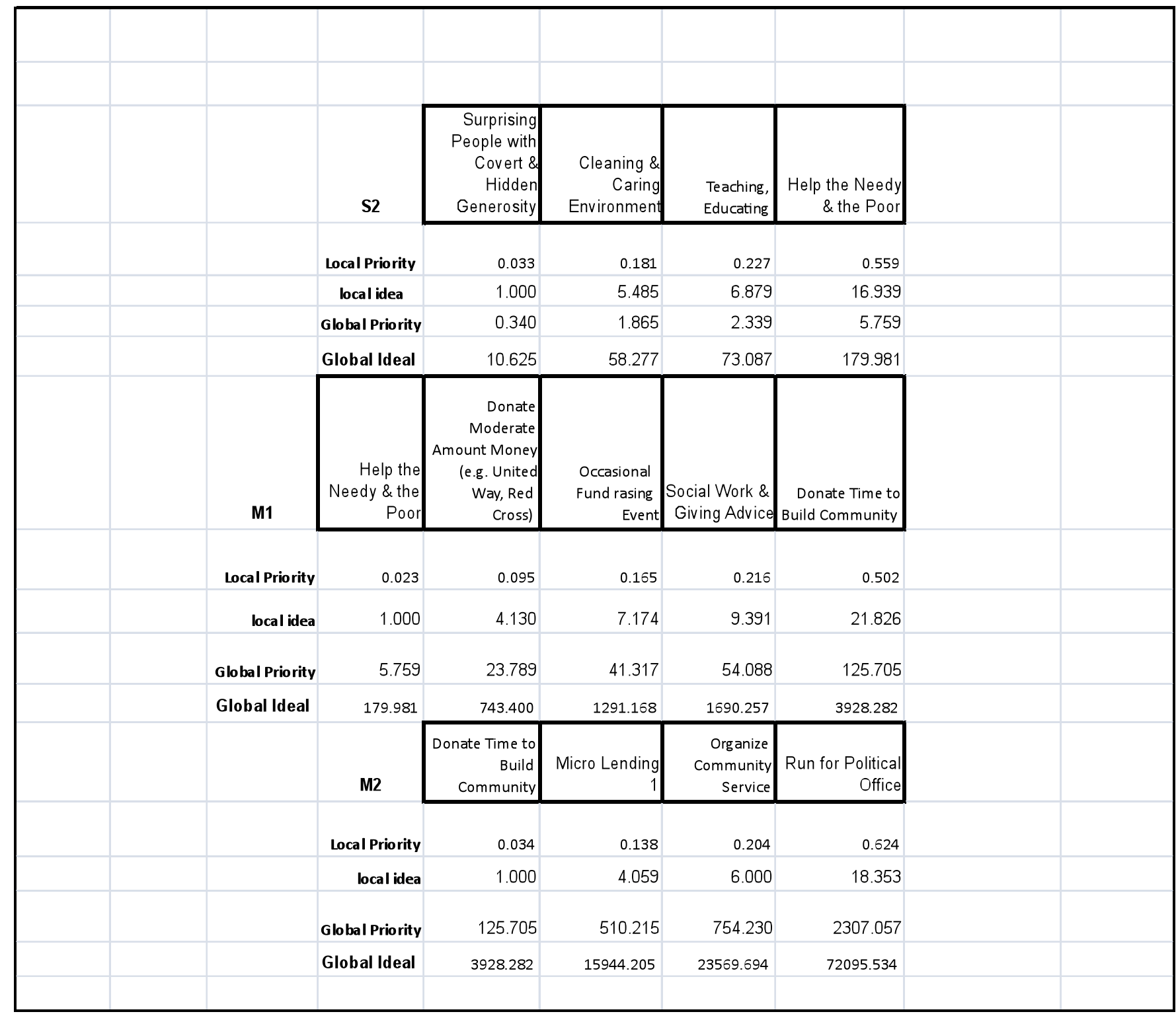


Table 1. The AHP model to prioritize the benevolent acts (Continued 2)

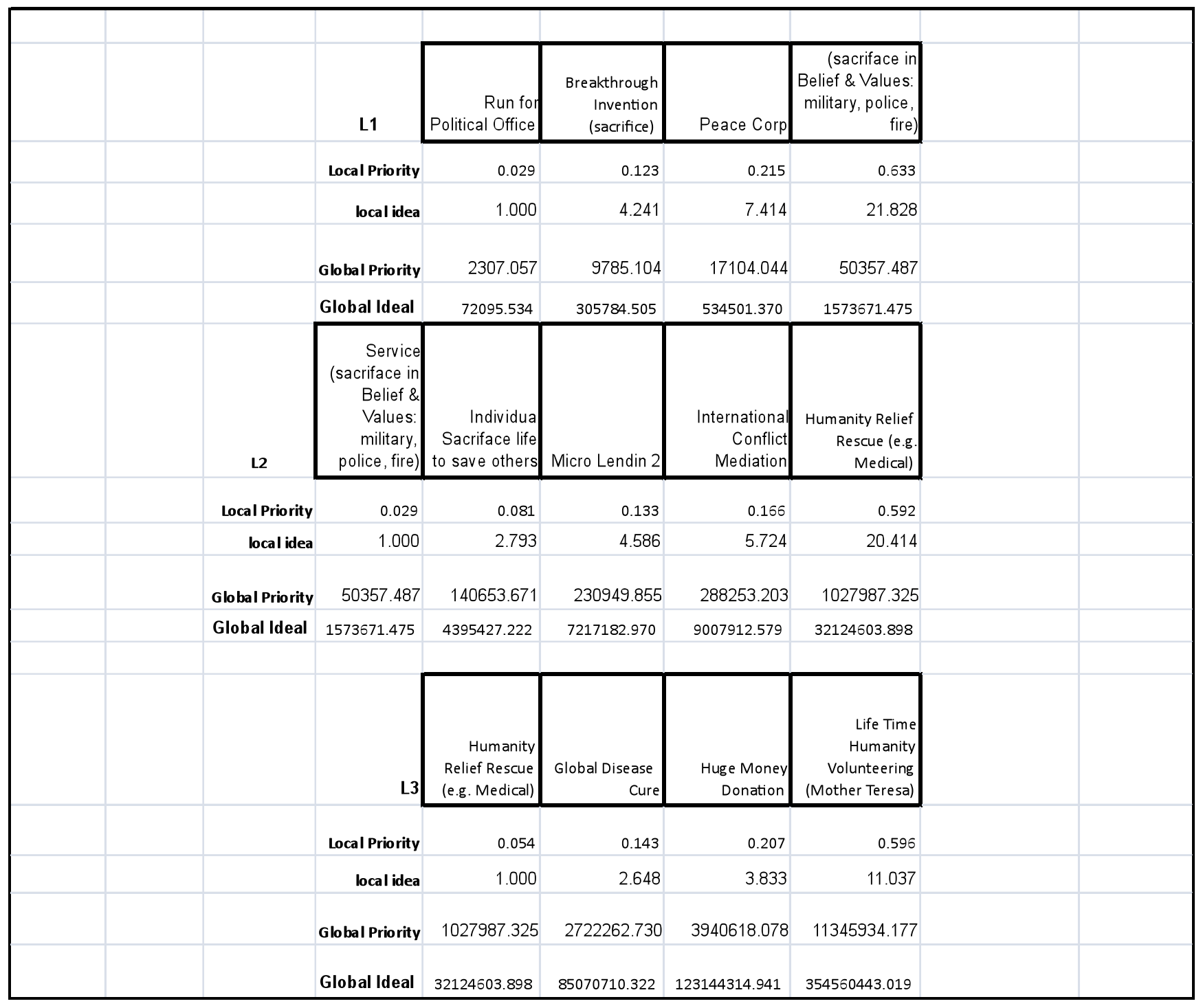


intermediate acts in Level M2. It is an innovative endeavor that grants small loans to poor people who have no collateral and do not qualify for conventional bank loans. By making small loans to help impoverished people start small businesses, it enables people, especially women, to start and develop their own small businesses. Many marginalized people can thus lift themselves out of poverty, and become market participants or even entrepreneurs.

(c) Big Acts

It is known that innovation and creativity are essential for a better and brighter future; and breakthrough inventions, the results of long and hard work, are the most important components driving technological and social progress. Journeys in innovation are unpredictable and full of uncertainty and sacrifice; the only sure thing the inventors can expect is its unexpected outcome.

Peace Corp promotes world peace and friendship. It encourages US citizens to help peoples around the world, under conditions of hardship if necessary, to make a real difference in other people's lives. Volunteers actively provide much needed assistance in a variety of areas, from HIV/AIDS activities, humanitarian assistance, post-conflict reconstruction to the needs in education and technology. Besides working for peace corp., many individuals sacrifice for the values they believed in, i.e. serving the military, police, fire station, etc.

Micro Lending 2 in level L2 provides a larger scale and amount of financial help than that described in Micro lending 1 above. It requires more complicated endeavor and additional localized understanding of the particular economic, cultural, and social factors affecting entrepreneurial success. Successful programs often invest lots of resources in training and support services. To alleviate long-term poverty, Micro Lending 2 would provide sustained and broad-based funding for education and training, housing, child care, and numerous infrastructure supports.

International conflict resolution aims at alleviating or eliminating sources of international conflict through mediation, negotiation, and diplomacy to resolve irreconcilable conflict in nations. The humanity relief rescues are relief efforts given in the time of natural (or political) disaster by individuals unilaterally offering time, labor, money, or goods. Finally, lifetime humanity volunteering like Mother Teresa did, advocates for the poor and helpless; provides hospices and homes for people with HIV/AIDS; takes care of people with leprosy and tuberculosis; sets up soup kitchens, children's and family counseling programs, orphanages, and schools. These volunteers sacrifice their life to provide service and ask for no return or compensation. Their acts are noble and deserve the highest level of respect

\subsection{Applying AHP to value intangible contributions to society}

In Figure 1, criteria are given on the top, while the different levels of benevolent acts are shown on the bottom with the smallest acts listed first. The seven levels of acts contribute to the society in a very different way, with different magnitude of significance. They cannot be compared directly since the largest one is far more important than the smallest one, a scale of 1 9 is not sufficient to represent their differences. Nevertheless, we can compare the elements in each level (group) on the larger scale to derive the local priorities, and then divide which by the weight of the pivot in that group and multiply by its weight from the previous smaller (less important) group to connect the different levels of importance. Eventually, the smallest act of courtesy and agreeableness is indirectly compared with the biggest act such as life time humanity volunteering.

It is done by first comparing courtesy and agreeableness with all the acts in the same (S1) level, such as complimenting people, keeping company \& comfort, etc. The act of surprising people with covert and hidden generosity is then again used in the S2 level, which includes cleaning and caring the environment, teaching and educating, and helping the needy and the poor. Next, we divide all the local weights in the $\mathrm{S} 2$ level by the local weight of surprising people with covert and hidden generosity (0.033), and then 
multiply all the resulting local idealized weights $(1,5.485,6.879,16.939)$ in this level by the global weight of surprising people with covert and hidden generosity (.34) in the S1 level to arrive at the Global priority..

Similarly, we include the act of run for political office in the L1 level of cluster. Pairwise compare and synthesize the matrix to find the local priorities $(.029, .123, .215, .633)$ for all L1 acts. Derive the local ideals by dividing every local weight by the smallest local weight, 0.029 . Multiplying the local ideals (1, $4.241,7.414,21.828$ ) by the global priority of Run for Political Office (2307) in the M2 level, we attain the global priorities for all L1 acts. In the same manner, we found the global priorities of the L3 acts are $(1,027,987 ; 2,722,263 ; 3,940,618 ; 11,345,934)$. In the end, we normalize all acts of all levels by dividing every act by the global priority of the smallest act weight, 0.032 (courtesy and agreeableness). Eventually, the global ideals are obtained, with $\mathrm{S} 1=(1.00,2.78,3.1,3.6,4.2,5.97,10.6) ; \mathrm{S} 2=(58,73,180)$ for modest acts. For intermediate acts $\mathrm{M} 1=(743 ; 1,291 ; 1.690 ; 3,928)$; $\mathrm{M} 2=(15,944 ; 23,570 ; 72,096)$; while for big acts $\mathrm{L} 1=(305,785 ; 534,501 ; 1,573,672) ; \mathrm{L} 2=(4,395,427 ; 7,217,183 ; 9,007,913 ; 32,124,604)$, and L3 $=(85,070,710 ; 123,144,315 ; 354,560,443)$

Now we have found the comparison of the smallest acts of courtesy and agreeableness with the biggest act of lifetime humanity volunteering. We have correspondingly extended the scale to $1 \sim 354,560,443$. The clustering approach adopted here is essential, since in most decision problems, there may be one or two levels of clusters and possibly it may go up to three or four adjacent ranges of homogeneous elements. Roughly we have in increasing order of importance: 1) modest acts, e.g. kind gesture and small help; 2) intermediate acts, e.g. sacrificing career, considerable time, and economic reward; 4) big acts, e.g. devoting lifetime, or significant part of one's life, money, and great risk to serve.

Contrary to many people's perception, the AHP scale in fact does not limit us if we know how to cluster similar objects in each group and use the largest element in a group as the smallest one in the next one, i.e. using it as a pivot to connect the two. Most important decision in life may need to consider at least two levels of categories. The priorities in the two adjacent levels should be sufficiently different, one being an order of magnitude much smaller than the other. Thus, in the synthesis, the priorities of the elements in the smaller set have little effects on the decision of the larger set. Using these concepts, comparing a very small thoughtful behavior (modest acts) with highly respectable and noble lifetime commitment to serve others (big acts) becomes possible.

\section{Conclusion}

To create a harmonious and happier society, all humankind should have the opportunity to contribute and to witness their value, through which people stand a better chance to sustain in the world and lead a more satisfactory life. Kostigen (2009) pointed out that there are various reasons for happiness: health, welfare, prosperity, leisure, strong family, social connections, etc. It is clear that money (prosperity) is not the only one, or the most important reason. A money-based system where people struggle for personal gain is no way to make the world a happier place. Some even said the love of money is the root of all evil. In the paper, we strive to downplay the importance of money and make people look at life from a different angle; put the people at the heart, and concentrate on what would be of real benefit to others.

Many problems faced in the world seem to be caused by the prevalent pursuit of self-interests. Newsweek columnist R.J. Samuelson (1992) wrote: "We face a choice between a society where people accept modest sacrifices for a common good or a more contentious society where group selfishly protect their own benefits. In recent years we have seen appeals to the common good, when discussing business' social responsibility, health care system, environmental pollution, education, and crime and poverty,. It is advised to consider replacing the "ethic of individual rights" with an "ethic of the common good". Examples of common goods include an accessible and affordable public health care system, and effective 
system of public safety and security, peace among the nations of the world, a just legal and political system, unpolluted natural environment, and a flourishing economic system (Velasquez et al. 1992).

This paper partly reflects on broad questions concerning the kind of society we aspire and want to pursue. While valuing the right of self-interest, as members of the society and citizens of the world, we need to recognize and further the altruistic undertaking to serve the great common good of the humanity we share in common. Based on our belief that people love one another and true happiness comes from seeing others happy, we identify many altruistic activities that people engage. These benevolent activities offer the possibility for people to reconnect with each other. Hopefully, we can alter the scarcity mentality, and make more people see the abundance and joy of life.

Human's needs in life provide the basis for our assessment of the variety of altruistic acts. The evaluations involve setting priorities and distinction, and the proposed AHP model provides a useful methodology to prioritize all criteria and activities in a scientific and systematic way. It is not the precision of measurement on a particular factor that determines the validity of evaluation results, but the importance we attach to the various criteria involved. So members of the society should participate and assign importance to all the factors and synthesize this diverse information to make the best distinctions among all acts.

From the AHP model, we see that each person's hour of service has different value. For that reason, the amount of money exchanged in any transaction should not be arbitrary or negotiable. To exchange the value of benevolent acts in more diverse communities where products or services may require a greater variety of skills, experience, training, equipment, or risk are exchanged, the proposed AHP model serve as a useful standard for the acts involved.

Through building a system that rewards generosity, not selfishness, we wish to re-establish altruism as a viable social norm. Using the economics of altruism, or gift economy as a breeding ground for altruism, we hope that the AHP's coherent approach would allow the world a chance to appreciate the power of getting back to altruistic roots and escape from win-lose mentality, shifting the frame of mind from scarcity to abundance.

\section{REFERENCES}

BBC News. 2006. Bhutan's happiness formula, http://news.bbc.co.uk/1/hi/in_pictures/4782636.stm

Gaye, A. Access to Energy and Human Development, Human Development Report 2007/2008. Fighting climate change: Human solidarity in a divided world. http://hdr.undp.org/es/informes/mundial/idh20072008/trabajos/Gaye_Amie.pdf.

Kostigen, T. http://www.marketwatch.com/story/the-happiest-places-on-earth-are-heavily-taxed, 2009.

Larimer, T. No Yen? No Problem! Small town bartering, 2006 http://www.time.com/ time/asia/features/changed_japan/yufu.html

LETSystem Design Manual, http://www.gmlets.u-net.com/design/ Accessed on June 16, 2009 
Lietaer, B. The Future of Money: Creating New Wealth, Work, and a Wiser World, 2001

Maslow, A.H. A Theory of Human Motivation, Psychological Review 50(4) (1943):370-96.

Samuelson, R. J. How Our American Dream Unraveled, 1992. http://www.newsweek.com /id/118553/ page/9. Accessed June 9, 2009

Velasquez, M., Andre, C., Shanks, T. S.J., and Meyer, M.J. The Common Good, Issues in Ethics. 5(2), Spring 1992. 